\title{
ETNOBOTÂNICA E ESTRUTURA POPULACIONAL DA MANGABEIRA (Hancornia speciosa Gomes) EM ASSENTAMENTO AGROEXTRATIVISTA, PIRAMBU, SERGIPE, BRASIL
}

\author{
ETHNOBOTANY AND POPULATIONAL STRUCTURE OF THE MANGABEIRA \\ (Hancornia speciosa Gomes) IN AGROEXTRACTIVE SETTLEMENT, PIRAMBU, SERGIPE, \\ BRAZIL
}

Thaiane Natalle Moreira LIMA ${ }^{1}$, Débora Moreira de OLIVEIRA ${ }^{2}$, Laura Jane GOMES ${ }^{3 *}$, Anabel Aparecida de MELLO ${ }^{4}$, Robério Anastácio FERREIRA ${ }^{5}$

${ }^{1}$ Mestre pelo Programa de Pós-graduação em Desenvolvimento e Meio Ambiente (UFS); ${ }^{2}$ Doutora pelo Programa de Pós-graduação em Desenvolvimento e Meio Ambiente (UFS); ${ }^{3}$ Doutora em Engenharia Agrícola (UNICAMP), Departamento de Ciências Florestais e do Programa de Pós-graduação em Desenvolvimento e Meio Ambiente (UFS); ${ }^{4}$ Doutora em Engenharia Florestal (UFPR), Departamento de Ciências Florestais (UFS); ${ }^{5}$ Doutor em Agronomia (UFLA), Departamento de Ciências Florestais e Pós-Graduação em Agricultura e Biodiversidade (UFS); *laurabuturi@ gmail.com

RESUMO

Submitted: 12/02/2019; Accepted: 04/05/2019

No Estado de Sergipe, o único Projeto de Assentamento de Reforma Agrária da modalidade Agroextrativista - o PAE São Sebastião - localiza-se no município de Pirambu, o qual foi criado com foco na geração de renda, decorrente do extrativismo e venda dos frutos da mangabeira (Hancornia speciosa Gomes; Apocynaceae). O presente estudo foi realizado com o objetivo de investigar os moradores do PAE São Sebastião quanto ao conhecimento e às formas de manejo da espécie, bem como analisar a estrutura populacional nos lotes produtivos. Foram realizadas entrevistas semiestruturadas e ferramentas do Diagnóstico Rápido Participativo (DRP) com 31 moradores do assentamento. A estrutura populacional foi avaliada por estágio de desenvolvimento e por classe de diâmetro, utilizando censo quali-quantitativo. Apesar dos moradores demonstrarem conhecimento sobre a espécie, observouse a necessidade de desenvolvimento de padronização dos métodos de coleta e manejo ao contrário do que é feito atualmente, que não resulte na quebra de galhos e derrubada de flores. Foram registrados 1.154 indivíduos de mangabeira, resultando em uma densidade de 14,5 indivíduos por hectare. Aparentemente, a população de $H$. speciosa no PAE São Sebastião não está em crescimento, pois apresenta predominância de indivíduos distribuídos nas classes de diâmetro intermediárias, o que pode comprometer a continuidade da atividade extrativista dos frutos no PAE.

Palavras-chave: Conservação; Extrativismo; Manejo Florestal; Mangaba; Produto Florestal Não Madeireiro.

\begin{abstract}
The only Agrarian Reform Settlement Project with the Agroextractive modality is located in the municipality of Pirambu, Sergipe State. Known as PAE São Sebastião, it was created with the focus on income generation from the extraction and sale of the fruits of mangabeira tree (Hancornia speciosa Gomes; Apocynaceae). The present study investigated the residents of the PAE São Sebastião in relation to their knowledge about and management forms of the species. The population structure of $H$. speciosa in the productive lots was also analyzed. Semi-structured interviews and tools of the Participatory Rapid Diagnosis (DRP) were performed with 31 residents of the settlement. Both the development stage and the diameter class, by means of a qualitative and quantitative census, were used in order to evaluate the population structure. The results indicate that the collectors have some knowledge about the species; however it is necessary to develop standardized methods of collection and management. The way it is currently done results in the breaking of branches and the felling of flowers. A total of 1.154 mangabeira trees were recorded, resulting in a density of 14.5 individuals per hectare. Apparently, the population of H. speciosa in the PAE São Sebastião is not growing, since it presents a predominance of individuals distributed in the intermediate diameter classes, which may compromise the continuation of fruit extractive activity in the area.
\end{abstract}

Keywords: Conservation; Extractivism; Forest Management; Mangaba; Non-timber Forest Product. 


\section{INTRODUÇÃO}

O Desenvolvimento Sustentável foi definido pela primeira vez no relatório intitulado "Nosso Futuro Comum" (CMMAD, 1987, p. 46) como "o desenvolvimento que procura satisfazer as necessidades da geração atual, sem comprometer a capacidade das gerações futuras de satisfazerem as suas próprias necessidades". Tal conceito serviu como base para questionamentos e o surgimento de novos paradigmas do conhecimento científico, que garantisse a troca de saberes entre a ciência e o conhecimento tradicional, a exemplo da agroecologia (GUIVANT, 1997).

Insere-se, nesse contexto, o uso de Produtos Florestais Não Madeireiros (PFNM) pelo homem, visto que são obtidos, em sua maioria, por meio do extrativismo e se apresentam como "um dos paradigmas da conservação" (TICKTIN, 2004), essencialmente porque se parte do princípio de que as práticas de exploração se aproximam do que é proposto pelo referido conceito, visando ao desenvolvimento sustentável.

Associado ao conceito de PFNM, há discussões de que esses produtos são mais fáceis de manejar e já foi considerado que se trata de estratégia que combina o desenvolvimento socioeconômico com baixo impacto ambiental (BRITES e MORSELLO, 2016). Por outro lado, Peters (1994) aponta que não há uma relação direta com a utilização de PFNM e a sustentabilidade de sua prática. Portanto, a afirmação de que o extrativismo de PFNM é, via de regra, sustentável, não corresponde a uma verdade absoluta (HOMMA, 2012), o que leva ao desafio atual de pesquisas que apontem se, de fato, ocorre o manejo florestal sustentável, de maneira particular, para cada espécie/localidade.

A lógica do manejo florestal sustentável parte do princípio de que as noções ecológicas que a população local possui constituem-se num instrumento primordial para a elaboração de estratégias de manejo, posto que reúnem informações de caráter ecológico, social e econômico que podem produzir planos de desenvolvimento mais adequados às condições do local (BERKES et al., 1999; GOMES et al., 2010). Por conseguinte, o manejo e a conservação do ambiente podem estar relacionados ao conhecimento ecológico local, como aponta a etnobiologia (POSEY, 1987).

Os estudos etnobiológicos têm o potencial de agregar e conectar os conhecimentos locais e globais, integrar culturas tradicionais e pesquisas acadêmicas, associar as relações biológicas e sociais da experiência humana no ambiente (ARAÚJO e ALBUQUERQUE, 2009), além de preencher lacunas no campo científico, através do conhecimento das comunidades locais e suas relações com os recursos naturais.

Quando os estudos etnobiológicos têm como foco espécies da flora, estas são estudadas pela etnobotânica, a qual, conforme Albuquerque (2002), se preocupa em entender a inter-relação direta entre pessoas de culturas viventes e as plantas de seu meio, aliando tanto fatores culturais quanto ambientais para entender as concepções dessas culturas sobre as plantas e o aproveitamento dado a elas.

No contexto das políticas públicas visando ao manejo florestal sustentável (INCRA, 2009), o Instituto Nacional de Colonização e Reforma Agrária (Incra) criou em 1996 a modalidade de Assentamento Agroextrativista. Apesar de existir a referida modalidade em outros Estados brasileiros, foi implantado em 2006 no município de Pirambu, Sergipe, o primeiro e, até o momento, o único Projeto de Assentamento Agroextrativista (PAE), denominado de Projeto de Assentamento Agroextrativista São Sebastião, o qual se destina à: "Exploração de áreas dotadas de riquezas extrativas, através de atividades economicamente viáveis, socialmente justas e ecologicamente sustentáveis, a serem executadas pelas populações oriundas de comunidades extrativistas" (INCRA, 1996, p. 1).

Neste sentido, o PAE São Sebastião surge como uma intervenção governamental, em um cenário de redução das áreas de coleta de mangaba, devido à expansão imobiliária e projetos de carcinicultura na região. A perda de áreas de mangaba tem ocasionado conflitos socioambientais diretamente relacionados aos proprietários de terras (SCHMITZ et al., 2009; RODRIGUES et al., 2017).

Durante estudos sobre o uso da flora pelas famílias assentadas no PAE, os pesquisadores Oliveira et al. (2018) constataram que predomina na comunidade o uso de espécies nativas do Brasil $(65,9 \%)$, com a mangabeira ocupando a terceira posição entre as espécies com maior valor de uso $(\mathrm{VU}=0,87)$ para a comunidade, o que, segundo os pesquisadores, confirma que a mangabeira está entre as espécies que têm alta importância para a subsistência e composição da renda familiar no assentamento.

Ressalta-se que a atual visibilidade e lucratividade associadas à mangaba, em Sergipe, têm aumentado a procura pelo fruto e seus coprodutos, o que pode ocasionar, conforme Ming et al. (2012), um avanço da exploração, de modo a colocar em risco a espécie por meio da redução dos estoques naturais, tendo em vista que, nesta atividade, na maioria das vezes, não se consideram os fatores de regeneração natural da espécie, a frequência e a intensidade da coleta de frutos. 
Deste modo, evidencia-se a necessidade de se realizar estudos sobre o conhecimento das populações extrativistas acerca das práticas de manejo empíricas empregadas nas atividades realizadas no PAE, bem como de se conhecer a estrutura populacional da mangabeira em seus remanescentes florestais e/ou em áreas cultivadas, a fim de gerar subsídios à proteção da espécie e garantir o uso sustentável por várias gerações e, ainda, para melhorar a renda das famílias extrativistas, tão necessária para o seu sustento.

Portanto, em relação ao extrativismo dos frutos da mangabeira no PAE São Sebastião, a presente pesquisa partiu dos seguintes questionamentos: Quais são as práticas relacionadas ao saber ambiental dos extrativistas? Qual a atual estrutura da população explorada? Nessa perspectiva, o presente estudo foi realizado com a finalidade de investigar os conhecimentos e as formas de manejo associados à espécie, bem como mensurar a estrutura populacional da mangaba nos lotes produtivos.

\section{METODOLOGIA}

\section{Área de estudo}

O estudo foi desenvolvido no Projeto de Assentamento Agroextrativista São Sebastião (PAE São Sebastião), único desta modalidade no Estado, situado nas coordenadas geográficas 10³6’15" S e $36^{\circ} 45^{\prime} 08^{\prime}$ ' W, localizado próximo ao povoado Alagamar, pertencente ao município de Pirambu, litoral de Sergipe, com uma distância média de 70 km da capital Aracaju (Figura 1).

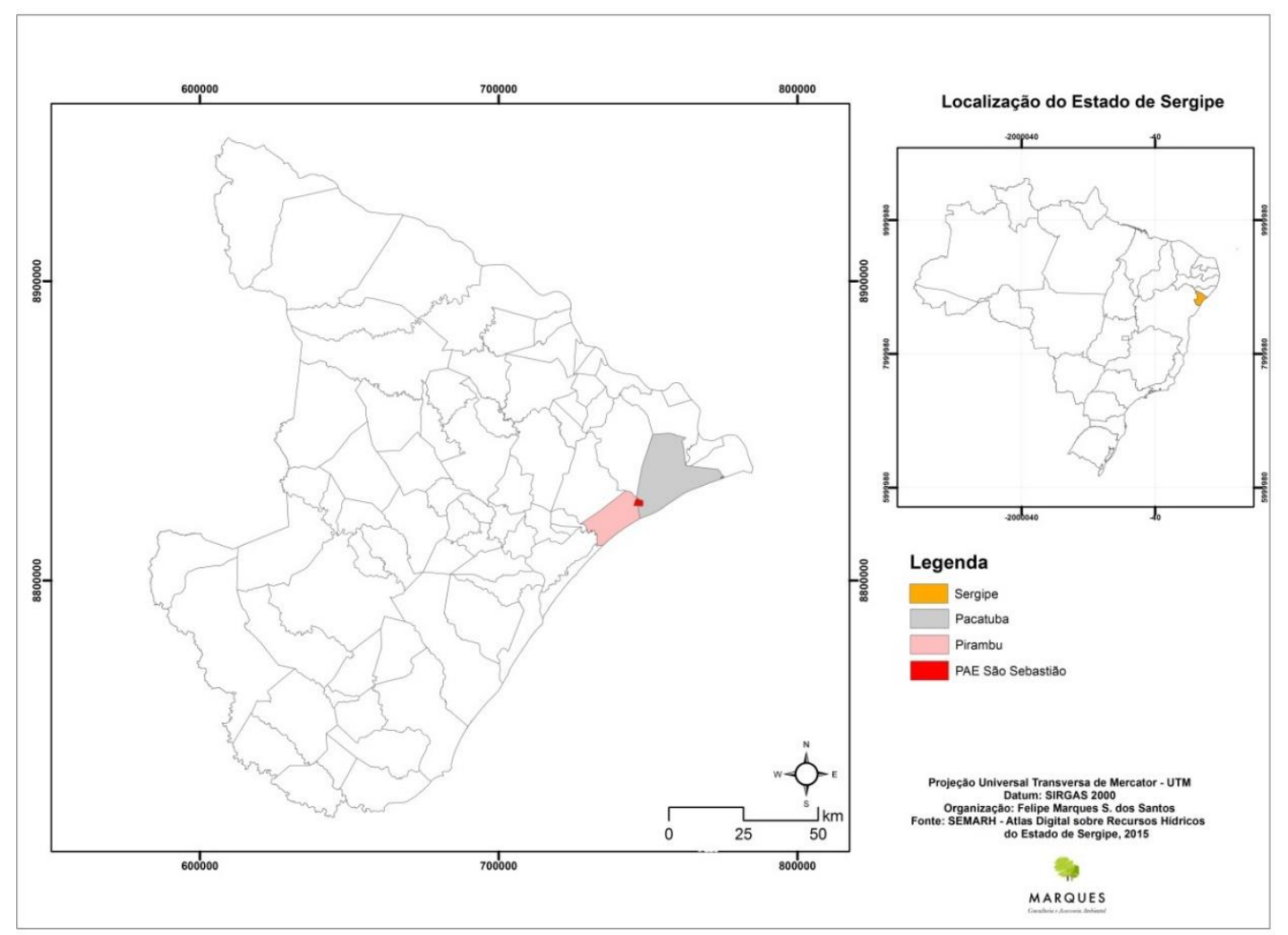

Figura 1: Representação cartográfica do Estado de Sergipe, do município de Pirambu e do Projeto de Assentamento Agroextrativista São Sebastião. Fonte: Base de dados da SEMARH-SRH (2015).

O assentamento está inserido na sub-bacia hidrográfica do rio Betume, principal tributário da bacia hidrográfica do rio São Francisco, em uma região próxima ao litoral do Estado de Sergipe, e foi instituído pelo Incra, através da portaria n- 23 de 18 julho de 2005 (INCRA, 2009), por meio da desapropriação de 610,312 hectares da antiga Fazenda Santa Isabel.

A vegetação da localidade, assim como do seu entorno, está dividida em restinga, manguezais, floresta de tabuleiros ou floresta estacional semidecidual (FRAGA, 2010). Convém ressaltar que a vegetação de restinga é protegida por lei, segundo o Novo Código Florestal Brasileiro, como área de preservação permanente (BRASIL, 2012). O relevo apresenta as unidades geomorfológicas de Planície Litorânea, contendo as planícies marinhas, a flúvio-marinha e a fluvial do rio Japaratuba; Tabuleiro Costeiro que abrange a Superfície Tabular Erosiva; Relevos Dissecados em Colinas e Interflúvios 
Tabulares. Os solos são Arenoquartizosos profundos, Arenoquartizoso Marinhos, Hidromórficos, Podzol e Podzólico Vermelho Amarelo (PCIHN, 2002).

A renda dos assentados advém, principalmente, do extrativismo dos frutos da mangaba (Hanconia speciosa Gomes), mas outras atividades são importantes para complementação da renda, tais como o extrativismo do ouricurizeiro (Syagrus coronata (Mart.) Becc.), atividades relacionadas à agricultura é composta pelo cultivo de coco (Cocos nucifera L), mandioca (Manihot esculenta Crantz), maracujá (Passiflora edulis Sims), melancia (Citrullus lanatus Thumb. Mansf.), abacaxi (Ananas comosus L. Merril,) batata-doce (Ipomoea batatas L. (Lam.)), amendoim (Arachis hypogaea L.) e milho (Zea mays L.), pecuária familiar, apicultura e pesca artesanal, além de benefícios advindos do governo, tais como aposentadoria, bolsa família, auxílio doença, bolsa verde e trabalhos não agrícolas, dentro e fora do assentamento.

\section{Estudo etnobotânico}

Em 2015, foi realizada a primeira reunião com os moradores, com destaque àqueles que realizam a coleta da mangaba, a fim de esclarecer quais eram os objetivos e a relevância da pesquisa, a metodologia a ser utilizada e a sua contribuição futura para as famílias do PAE. Após a apresentação da proposta da pesquisa, solicitou-se aos assentados para que assinassem o Termo de Consentimento Livre e Esclarecimento. O estudo foi aprovado pelo Comitê de Ética e Pesquisa da Universidade Federal de Sergipe.

A citação dos entrevistados foi feita de modo a não os identificar, conforme estabelecido por Brasil (1996), e foram utilizadas as letras $\mathrm{H}$ e M para homens e mulheres, respectivamente, seguidos dos números de identificação e idade (exemplo: H9, 50 anos).

Foram realizadas entrevistas semiestruturadas e a escolha deste instrumento de pesquisa se deve ao fato de proporcionar maior liberdade de expressão do entrevistador e entrevistados, o que permite o aprofundamento de elementos que possam surgir na entrevista (ALBUQUERQUE et al., 2010). As entrevistas ocorreram simultaneamente à época de coleta dos frutos, entre os meses de janeiro e junho de 2016, a fim de observar as práticas de coleta, beneficiamento pós-colheita, manejo empregado pelos extrativistas. Também foram aplicadas ferramentas do Diagnóstico Rápido Participativo (VERDEJO, 2007), a saber: histórico de produção, calendário agrícola e rotina diária.

Para a escolha dos entrevistados, foram adotados os seguintes critérios: 1) Das 28 famílias residentes no Projeto de Assentamento Agroextrativista, 24 foram entrevistadas, 04 foram excluídas da pesquisa por não realizarem atividades de coleta dos frutos; 2) Pelo menos um integrante de cada uma das 24 famílias que coletam os frutos da mangabeira foi entrevistado. Porém, totalizou-se 31 entrevistas, pois em algumas famílias mais de um componente estava atuante na coleta e mostrou-se disposto a participar da pesquisa.

Portanto, ressalta-se que a amostragem utilizada foi não probabilística do tipo intencional em que não se tem uma preocupação com o uso de cálculo estatístico para definir a amostra dos entrevistados, mas sim, entrevistar o maior número de pessoas dispostas a fornecer informação relacionada à atividade (MARCONI e LAKATOS, 2010).

A análise quali-quantitativa desta etapa da pesquisa foi feita com a utilização da técnica do Discurso do Sujeito Coletivo (DSC), proposto por Lefreve e Lefreve (2005), a qual, para os autores, constitui-se de discursos formados a partir de expressões-chave de vários depoimentos de diferentes pessoas que buscam descrever opiniões e posicionamentos sobre determinado tema, em grupo sociocultural selecionado. Por se tratar de uma análise qualitativa, um mesmo entrevistado poderá se enquadrar em mais de um DSC ou nas respostas apresentadas; neste sentido, optou-se por apresentar os resultados em número de entrevistados e não em porcentagens.

\section{Estrutura populacional da mangabeira}

Essa etapa da pesquisa ocorreu entre os meses de fevereiro e outubro de 2016. Optou-se por avaliar a estrutura populacional da mangabeira dos lotes produtivos, uma vez que esta é, segundo os entrevistados, a principal área de coleta de mangaba no PAE São Sebastião. Convém ressaltar que, da área total do assentamento, cerca de 79,6 ha são utilizados como lotes produtivos, o que dá uma média de 2,84 ha para cada família. Além dos lotes produtivos, há também o núcleo urbano do assentamento que está organizado na forma de agrovila, onde as residências ficam próximas umas das outras (SANTANA, 2012).

A quantidade de lotes produtivos não é referente ao número de famílias (28), pois algumas delas (14) possuem mais de um lote, a fim de equalizar a área total dos lotes para cada família. Foram 
selecionados 44 lotes produtivos utilizados e indicados pelos moradores. Os lotes foram avaliados quanto à intensidade de manejo, número de indivíduos de mangabeiras, cultivos, tamanho e características ambientais nas proximidades em que estão inseridos. Após avaliação, os lotes receberam uma numeração de acordo com a ordem de avaliação em campo e foram agrupados e caracterizados em áreas.

Foi realizado um censo quali-quantitativo em todos os lotes com o intuito de descrever a estrutura populacional da espécie por estágio de desenvolvimento e por classe de diâmetro. Assim, em cada lote foram registrados todos os indivíduos de mangabeira com circunferência igual ou superior a $15,7 \mathrm{~cm}$ a $30 \mathrm{~cm}$ do solo $\left(\mathrm{CA}_{30}\right)$. Posteriormente, esses valores foram convertidos em diâmetro a $30 \mathrm{~cm}$ do solo $\left(\mathrm{DA}_{30}\right)$ para caracterizar a estrutura populacional. Para os indivíduos com $\mathrm{DA}_{30}$ inferior a $5 \mathrm{~cm}$, mediu-se o diâmetro no nível do solo (LIMA, 2008). A mensuração da circunferência foi feita com a utilização da fita métrica e o diâmetro com o auxílio de um paquímetro. Para os indivíduos com mais de um fuste, foi calculado o diâmetro equivalente.

Os indivíduos medidos foram classificados em estágios de desenvolvimento, com significado biológico, mas que não indicam necessariamente a idade dos indivíduos, com base no diâmetro e na intensidade da fase reprodutiva, como proposto por Lima (2008) em trabalho realizado com mangabeira no Cerrado. Assim, os estágios de desenvolvimento foram estabelecidos como:

- Juvenis: os indivíduos que possuem até $5 \mathrm{~cm}$ de diâmetro no nível do solo e que ainda não atingiram a fase reprodutiva;

- Reprodutivos jovens: indivíduos que possuem de 5 a $20 \mathrm{~cm}$ de diâmetro à altura de $30 \mathrm{~cm}$ do solo e que estão no início da fase reprodutiva;

- Reprodutivos maduros: indivíduos que possuem mais de $20 \mathrm{~cm}$ de diâmetro à altura de 30 cm do solo e cujos indivíduos estão no auge da fase reprodutiva, com máxima frutificação.

Para análise da distribuição diamétrica, foram determinadas arbitrariamente 11 classes de diâmetros para possibilitar a comparação entre os lotes, delimitando-se como amplitude da classe, $5 \mathrm{~cm}$. A partir da distribuição dos indivíduos de mangabeira por lote, por estágio de desenvolvimento e por classe, foi analisada a estrutura populacional.

\section{RESULTADOS E DISCUSSÃO}

\section{Práticas relacionadas ao saber ambiental dos extrativistas}

Conforme metodologia utilizada, por meio das entrevistas, constatou-se que, no período de produção dos frutos, os extrativistas dedicam a maior parte do seu tempo diário à coleta. Por meio do calendário agrícola e fenológico da espécie, foi possível identificar, ainda, qual o período de início e fim das safras, o período de floração e de produção dos frutos.

Foram identificados dois períodos de safra. O primeiro, denominado como safra de verão, tem início no mês de dezembro e término no final de março, podendo se estender um pouco até o mês de abril. O início da floração nesta primeira safra é nos meses de outubro e novembro e, em dezembro, as mangabeiras começam a produzir os frutos. O segundo período, denominado safra de inverno, tem início no fim do mês de maio e término no mês de julho e, nesta safra, o início da floração é no mês de maio.

Acompanhando as famílias durante a atividade extrativista e, por meio das entrevistas, foi possível observar/constatar que a coleta dos frutos é realizada por dois métodos e de forma simples. No primeiro método, os frutos são coletados manualmente e diretamente da árvore, com o auxílio de ganchos e, por vezes, houve relatos de que sobem nas árvores. No segundo método, os frutos são coletados no chão, após a sua queda, quando estes atingem o seu ponto de maturidade fisiológica e são dispersos em função do seu peso (barocoria). Neste caso, observa-se que os frutos estão bem maduros. Os entrevistados afirmaram que, durante a coleta, não selecionam as plantas que terão os frutos coletados, mas, sim, que vão retirando à medida que visualizam as árvores com frutos.

Assim, foi possível identificar quatro Discursos do Sujeito Coletivo (DSC), com base na Ideia Central (IC) de que os moradores: coletam os frutos, subindo nas árvores, porque não há quebra dos galhos; coletam com um gancho e com as mãos; coletam do chão, para não machucar a mangabeira; não coletam do chão, conforme a composição de expressões-chave (Ech) descritas a seguir, considerando que alguns entrevistados se enquadraram em mais de um DSC: 
$\mathrm{DSC}^{1}$ "Subo na árvore porque assim não quebro os galhos nem machuca a planta" (10 entrevistados).

DSC “Cato no pé, com o gancho e as mãos” (17 entrevistados).

$\mathrm{DSC}^{3}$ "Eu cato do chão porque assim não judia a planta” (7 entrevistados).

$\mathrm{DSC}^{4}$ "Não panho (pego) do chão ou porque não tem fruto caído, ou porque tá mordida de besouro e ela fica ruim" (3 entrevistados).

Pode-se afirmar que a ausência de orientação técnica faz com que ocorram várias formas de coleta dos frutos. Os entrevistados não seguem um padrão, além de terem apresentado diferentes percepções quanto à maneira de coleta - para uns, subir na árvore não "machuca" a planta, enquanto outros apenas coletam do chão para não ter contato com a planta e vir à "machucá-la".

Os frutos coletados também recebem diferentes denominações, de acordo com a forma de coleta, utilizando-se os termos: "de vez" (10 entrevistados), frutos que estão quase caindo do pé; "apaé" (10 entrevistados), considerado quando os frutos estão "inchados" (o que significa que os frutos encontramse numa fase intermediária entre verde e maduro); os frutos que estão no chão ou "de queda" (5 entrevistados). Os frutos verdes não são coletados. Neste caso, os extrativistas retornam na semana seguinte ou três dias após para realizar a coleta destes frutos.

Os frutos "de vez" e "apaé" são coletados diretamente nas árvores. Para tanto, o maior número de entrevistados sobe nas árvores ou utilizam o gancho. Em estudos realizados por Lima (2008) e em documento de Boas Práticas de Manejo da Mangaba, elaborado em 2011 (LIMA e SCARIOT, 2011), com a participação de extrativistas da mangaba de várias regiões do Brasil, sugeriu-se coletar os frutos com o gancho para evitar a quebra dos galhos e não prejudicar a produção dos frutos no ano seguinte. A quebra dos galhos também favorece o surgimento de doenças e ataque de insetos.

Em adição, Kramer (1972) afirma que a produção dos frutos é prejudicada em consequência da eliminação de folhas nos ramos e queda das flores causadas pela queda dos galhos, havendo redução da produção fotossintética e, consequentemente, uma redução na quantidade de carboidratos. Isto, provavelmente, implica em desgaste fisiológico para as plantas, que precisam recompor o seu status nutricional para suportar a produção de flores e frutos, nas épocas seguintes.

Além disso, Lima (2008) e Lima e Scariot (2011) sugeriram: não coletar todos os frutos da mangabeira para não comprometer a perpetuação da espécie; evitar a derrubada das flores para não afetar a produção de frutos; não coletar a mangaba verde, pois os frutos não irão amadurecer (por não serem climatérios); coletar os frutos "de vez"; realizar as coletas durante toda a safra, uma vez que o processo de maturação ocorre de maneira desuniforme ao longo do período de produção (safra).

Quanto ao total da produção, ele varia em quantidade de frutos coletados em razão da safra (e todas as variáveis já citadas com relação ao manejo durante a coleta), da quantidade de dias em que se realiza a coleta, das áreas onde os frutos são coletados, bem como pode depender também do comprometimento e práticas aplicadas, o que não foi possível estimar neste estudo.

A atividade pós-colheita é realizada estritamente pelas mulheres. Elas lavam os frutos da mangaba para a higienização e eliminação da exsudação do látex (leite). Duas mulheres lavam os frutos com água clorada (fornecida pela Companhia de Saneamento de Sergipe), o restante lava apenas em água corrente (de poço ou rio). Após serem lavados, os frutos são secos ou apenas colocados em uma vasilha, ou sobre um pano de algodão para escorrer. Esta operação é realizada sempre à sombra, pois, segundo as entrevistadas, se forem secos ao sol, liberam mais látex (leite) e grudam mais.

A recomendação, nesta situação, é que os frutos devem ser lavados em água clorada ( 25 ppm de cloro livre), contendo detergente (5\%) e, em seguida, enxaguados com água clorada novamente (10 ppm de cloro livre) (LEDERMAN et al., 2000). Esse procedimento facilita a eliminação da exsudação de látex. Contudo, os assentados não demonstraram ter esse conhecimento.

Após a secagem, os frutos são selecionados, descartando-se os danificados ou "doentes". Em seguida, são colocados em baldes ou caixas para aguardar o atravessador ou para serem processados na agroindústria, localizada no próprio assentamento.

A mangaba "de caída" - quando a mangaba atinge a sua maturidade na planta e cai no solo deve ser logo vendida ou congelada, pois possui vida útil curta (NOGUEIRA e ALBUQUERQUE, 2006), ou seja, é um fruto que se "perde" rápido. Estes frutos amadurecem entre 12 e 24 horas e são muito perecíveis (VIEIRA NETO et al., 2006). Segundo os entrevistados, estes são os frutos mais solicitados por consumidores, o que corrobora com o estudo de Silva Junior et al. (2003), que afirmam 
que as mangabas que caem no solo ("de queda" ou "de caída") possuem teores de sólidos solúveis superiores aos dos frutos coletados na planta ("de vez"), ou seja, são frutos menos ácidos e mais adocicados, por isso, são mais apreciados pelos consumidores.

Em contrapartida, existem diferentes compreensões quanto à qualidade dos frutos. Em trabalho desenvolvido por Fernandes e Mota (2014), na região Norte do Brasil, as apanhadoras de mangaba consideram que as que se encontram no chão não são boas para o consumo, por já estarem em processo de apodrecimento. Em adendo, os frutos "de queda" não são recomendados para comercialização, isso devido à sua curta vida útil pós-colheita, associada a aspectos de segurança alimentar. Logo, Parente et al. (1985) e Aguiar Filho (1998) afirmam que, para a comercialização, os frutos devem ser colhidos "de vez", como foi também enfatizado pelos entrevistados na presente pesquisa.

Segundo os entrevistados, as maiores dificuldades na atividade são: a volta para casa, devido ao peso e distância dos lotes ( 8 entrevistados) - uma vez que alguns lotes ficam a mais de $7 \mathrm{~km}$ da agrovila; falta de união (8 entrevistados); a baixa produção dos frutos (7 entrevistados). Também existe uma relação de afetividade com a atividade, como é possível perceber no comentário: "Eu gosto quando chego lá e vejo os pés tudo amarelo. Eu acho tão bonito. Eu adoro" (24M, 51 anos).

Quando questionados se possuem mangabeira de origem cultivada, constatou-se que, das 24 famílias, 21 possuem exclusivamente mangabeiras nativas em seus lotes e em três famílias os entrevistados afirmam ter cultivado entre os indivíduos nativos. Convém destacar que o enriquecimento das áreas de mangabeira foi realizado pelos assentados de forma empírica, pois afirmam não terem recebido assistência técnica especializada.

Cinco entrevistados tentaram cultivar mangabeira por meio de semeadura, sendo que um entrevistado (19 H, 60 anos) afirmou que as sementes não germinaram. Para outros quatro entrevistados, as sementes germinaram. Verificou-se que os procedimentos para o cultivo foram realizados de formas diferentes, como indicam as falas transcritas a seguir:

"Lavei a mangaba, tirei a semente, botei nos copos e um tempinho depois plantei. Foi pouca as que morreu. Quando tá plantando pega um pouquinho de adubo e bota nos pés dele/maço e chuê. O adubo é o que compra no saco" (6M, 41 anos).

"Lavei as sementes, coloquei para secar na sombra, peneirei a terra no fundo do quintal. Não pode passar a mão com força na peneira. Bota para secar um pouco. Plantei ano passado 20 pés, tem 15 que pegou no lote. Tem que ter cuidado porque se pegar vento na raiz, morre" (8 M, 47 anos).

"Plantei a semente numa bolsa só com areia. Só limpa depois que planta. Quando cresce a muda, planta ela no lote. Não coloco adubo nem nada. Espera um ano para plantar" (16 H, 56 anos).

"Planto com semente e deixo na roça secando por dias na sombra. Preparo a terra, faço o "lambico" e saio plantando. Espaço de $2 \mathrm{~m} \mathrm{em} 2 \mathrm{~m}$. Não planto as filhas (plântulas naturais das mangabeiras) porque estão muito enraizadas" ( $21 \mathrm{H}, 49$ anos).

Dois entrevistados afirmaram que elas apresentam o primeiro par de folhas a partir do $45^{\circ}$ ao $60^{\circ}$ dia, após o plantio, ou seja, as sementes levam de 45 a 60 dias para emergirem as plântulas e levaram de 4 a 5 anos para produzirem frutos.

Outros seis entrevistados afirmaram já terem plantado mangabeiras a partir das plântulas, ou seja, eles retiraram as plântulas do local onde estavam enraizadas e as transferiram para o local desejado. Destes, destaca-se a experiência de uma moradora (7 M 54 anos), que além de evitar o transplante no período do verão, as plântulas geralmente não suportam as mudanças de local, sendo exigentes a alguns fatores, por isso é necessário dispensar uma maior atenção (regas) às plantas transplantadas.

No Manual de Boas Práticas da Mangaba há a indicação da forma mais adequada de se realizar o cultivo da mangabeira, porém os procedimentos descritos pelos entrevistados na presente pesquisa não coincidiram com os recomendados por Lima e Scariot (2011).

Constatou-se que os entrevistados realizam diversas formas de manejo nos pés de mangabeiras e ao redor deles: retiram a "ramada", denominada como erva de passarinho, que nasce sobre as árvores, caso contrário morrem ( 3 entrevistados); limpam os pés de mangabeira e roçam ao redor, não deixando o mato dominar a mangabeira, pois o mato dificulta o desenvolvimento da planta, além de atrapalhar a coleta (14 entrevistados); aplicam adubo (3 entrevistados) ou utilizam apenas as folhas do chão como 
adubo orgânico (2 entrevistados); juntam as folhas que caem da mangabeira e queimam embaixo da planta para que, assim, as folhas que ainda estão na árvore queimem. Em seguida, os galhos renovam com flor e, posteriormente, surge o fruto (5 entrevistados); realizam a poda para que a planta renove com galhos e flores (2 entrevistados).

Um entrevistado que realiza o plantio de mangabeira em seu lote afirma que retira algumas plântulas da área e realiza o plantio em outros trechos do lote, pois os indivíduos nascem muito próximos e, segundo ele, os indivíduos crescem, mas não produzem frutos. É importante afirmar que os moradores não utilizam técnicas de irrigação.

A mangabeira só se desenvolve quando o pé está "zelado" (limpo, roçado), ou quando não se encontra em área de mata, pois quanto mais aberta a área, maior a concentração de indivíduos e, consequentemente, melhor é o desenvolvimento da espécie.

Quando questionados quanto à causa da morte dos indivíduos, os entrevistados responderam: o "calor" e o "verão" são os responsáveis por matar as mangabeiras (3 entrevistados); elas morrem devido à idade, os indivíduos estão velhos (3 entrevistados); o que mata a mangabeira é o "enxerto", "mancheco" ou erva de passarinho que se entrelaça na mangabeira e se alimenta do seu látex (4 entrevistados).

Para alguns entrevistados, a mangabeira vive muito e, segundo eles (7 entrevistados), ela pode chegar a 30 anos. Acrescentam, ainda, que existem plantas com altura superior a das casas e que esses indivíduos estão no PAE desde antes da ocupação da área.

Os entrevistados foram questionados se já observaram alguma doença na mangabeira. Deles, 10 afirmaram que sim e estes foram indagados sobre como combateram a doença. Foi possível formar dois DSC, conforme demonstrado abaixo:

DSC 5 "Tem a planta que rama nela e mata, amarela as folhas. É comum. O "mancheco" enlinha nela. Aí ele rama, vai ramando e aí mata. Mata até o cajueiro também. Tem que tirar sempre porque eles não morrem nunca e matam a mangaba" (4 entrevistados).

$\mathrm{DSC}^{6}$ "O cupim causa doença. Eu coloco veneno ou então coloco o calor do fogo para matar ele" (2 entrevistados).

$\mathrm{DSC}^{7}$ "A lagarta causa doença” (3 entrevistados).

Além disso, um entrevistado afirmou que além do erva de passarinho, há outro tipo de "rama" a qual as folhas são mais compridas. Ele combate essa "rama" retirando-a das mangabeiras. É importante afirmar que os termos "mancheco", "enxerto" e "erva de passarinho" são palavras que se referem ao mesmo dano causado à mangabeira.

Uma questão importante levantada pelos entrevistados (5) é que alguns indivíduos de mangabeira perdem as suas folhas antes de "botar" o fruto, e quanto mais folhas se perde, mais fruto o indivíduo produz. Com isso, alguns entrevistados afirmaram queimar os galhos secos da mangabeira, o que ocorre entre os meses de dezembro a fevereiro.

A mangaba produzida na primeira safra (verão) apresenta o fruto mais claro e amarelado. Diferente desta, a mangaba produzida na segunda safra (inverno), que é no período das chuvas, é mais escura e avermelhada. Em estudo desenvolvido por Silva Junior et al. (2003), comprovou-se que a coloração dos frutos no inverno não compromete o sabor da mangaba, no entanto, segundo os entrevistados, a mangaba de inverno não é tão saborosa quanto a mangaba de verão, sendo menos adocicada.

\section{Estrutura da população de mangabeira explorada}

Constatou-se que os lotes estão submetidos a diferentes intensidades de coleta e manejo, não havendo padronização quanto ao tamanho, cultivos, número de indivíduos de mangabeiras e quanto às características ambientais onde estão inseridos (proximidade ao rio, solo encharcado, área com declividade, com vegetação dentro ou no entorno). Assim, as áreas e os lotes receberam uma numeração, de acordo com a ordem de avaliação em campo (por exemplo: Área I, primeira a ser avaliada em campo). Os lotes estão agrupados nas seguintes áreas:

Área I- Composta por nove lotes, os quais estão situados próximos a uma região denominada pelos moradores como "Gomes", parte pertencente à reserva legal, e próximos à agrovila do assentamento. Os lotes estão dispostos lado a lado, possuem trechos encharcados e há vegetação nativa próxima. Há o predomínio de coco cultivado, mandioca e áreas naturais com ouricuri e mangabeira, 
além da existência de pastagem em cinco lotes (lotes 1, 3, 4, 9 e 10). A coleta dos frutos da mangaba não é intensa nessa área.

Área II- Composta por 12 lotes, os quais estão localizados próximos ao rio Betume, com vegetação nativa dentro e no entorno. Os lotes estão situados em um ambiente com declividade média e acentuada, dispostos lado a lado, exceto quando há trechos com vegetação nativa que os separa. Os lotes dessa área são bem manejados, com destaque para os lotes 12,13 15, 19 e 31. Os trechos dos lotes em que há cultivo são roçados e limpos, principalmente os lotes onde há intensa coleta de mangaba. Entre as culturas, tem-se coco, abacaxi, mandioca, batata doce e milho e áreas naturais com mangabeira e ouricuri. Sete lotes possuem áreas com pasto, sendo que, em alguns, os pés de mangabeira estão entre pastagens e em outros, a área de pastagem é cercada (lotes 11, 12, 13, 15, 16, 17 e 20).

Área III- Agrupa 13 lotes localizados na área de preservação permanente (APP) do rio Betume. Todos os lotes alocados nessa área possuem uma parte significativa de trechos encharcados. Não há intensa extração de mangaba. Entre as culturas existentes, tem-se coco e mandioca e áreas naturais com mangabeira e ouricuri. Sete lotes possuem áreas com pastagem (lotes 21, 22, 23, 28, 32, 33 e 34).

Área IV-Composta por dois lotes próximos ao povoado Alagamar e da estrada que liga o povoado ao assentamento. Os lotes dessa área estão localizados na reserva legal. Em um deles (lote 36), há intenso extrativismo da mangaba. Há, nesse lote, o cultivo de coco e abacaxi e áreas naturais de mangabeira e ouricuri, e tudo é bem manejado. O outro lote (35) é área de pastagem e há cultivo de coco e mandioca, sendo que parte dele ainda não foi utilizado pelo proprietário.

Área V-Composta por três lotes. É a área mais distante da agrovila do PAE e de todas as outras áreas. Essa área está situada em uma região pouco explorada, próximo à reserva legal. Dos três lotes agrupados, um não foi utilizado pelo proprietário. Há vegetação dentro e no entorno dos lotes, bem como presença de nascentes. Um dos lotes (37) se destaca pelas práticas de manejo empregadas, com cuidados de limpeza, e há intensa coleta de mangaba. Há, na área, o cultivo de maracujá, coco, abacaxi, milho e amendoim e áreas naturais com mangabeira. Observou-se ainda, neste lote, a criação de abelhas para a produção de mel. Dois lotes possuem pasto (37 e 38). No entanto, em um lote, a área de pasto é separada das outras áreas de cultivo.

Área VI- Composta por cinco lotes e corresponde a uma das áreas mais distantes da agrovila do PAE e de todas as outras áreas. Está situada na reserva legal. Não há intensa extração de mangaba, exceto no lote 41 . Há cultivo de amendoim, coco e mandioca e existem áreas naturais com ouricuri e mangaba. Todos os lotes pertencentes a essa área possuem pastagem.

Nos lotes produtivos, foram registrados todos os indivíduos de mangabeira encontrados, desde plântulas até indivíduos em fase reprodutiva (jovens e maduros). No total, foram registrados 1.154 indivíduos, resultando em uma densidade de 14,5 indivíduos por hectare, distribuídos nas seis áreas e 44 lotes (Tabela 1).

Dos lotes estudados, em 12 deles não foi registrado nenhum indivíduo de mangabeira. Desses lotes, três estão localizados na área I, um na área II, cinco na área III, um na área V e dois na área VI.

A discrepância quanto ao número de indivíduos nos lotes pode ser explicada através da descrição das características ecológicas e ambientais onde eles estão inseridos. A mangabeira se desenvolve em solos pobres e de textura arenosa, não suportando encharcamento (VIEIRA NETO et al., 2006), o que explica o baixo número de indivíduos nos lotes das áreas I e III, os quais se encontram estabelecidos em áreas planas e encharcadas, além de os lotes da área III estarem sob a área de preservação permanente (APP) do rio Betume.

O histórico de ocupação, aliado ao nível de antropização dos lotes, também pode estar contribuindo para a disparidade quanto ao número de indivíduos por lote. Os lotes situados próximos às áreas, com remanescentes de vegetação nativa $(13,15,31,36,37)$, avançaram nas áreas de mata por meio das práticas de manejo de capinas e queimadas. Pode ser que essas práticas possam ter favorecido o surgimento de mangabeiras, como resultado da abertura de dossel. Curiosamente, esses lotes representam 61,95\% (715) dos indivíduos encontrados na área de estudo. A mangabeira é uma espécie pioneira e a principal característica dessas espécies é que são exigentes quanto à luminosidade para a germinação, a sobrevivência e o crescimento (NOGUEIRA e ALBUQUERQUE, 2006). Ademais, não podem regenerar in situ sobre sua própria sombra. 
Lima et al. Etnobotânica e estrutura populacional da mangabeira (Hancornia speciosa Gomes) em Assentamento Agroextrativista, Pirambu, Sergipe, Brasil. Ethnoscientia 4, 2019. DOI: 10.22276/ethnoscientia.v4i1.207

Tabela 1: Número de indivíduos de mangabeira por lote, hectare e área de ocorrência no PAE São Sebastião, Pirambu, Sergipe.

\begin{tabular}{|c|c|c|c|c|c|c|}
\hline Áreas & Lotes & Tamanho dos lotes (ha) & Indivíduos /lote & Indivíduos /lote/há & $\begin{array}{l}\text { Indivíduos } \\
\text { /área }\end{array}$ & $\begin{array}{l}\text { Indivíduos } \\
\text { /área/ha }\end{array}$ \\
\hline \multirow{9}{*}{ I } & 1 & 1,68 & 0 & 0 & \multirow[t]{9}{*}{72} & \multirow[t]{9}{*}{6,1} \\
\hline & 2 & 0,94 & 0 & 0 & & \\
\hline & 3 & 0,86 & 0 & 0 & & \\
\hline & 4 & 1,68 & 18 & 10,7 & & \\
\hline & 5 & 1,49 & 2 & 1,3 & & \\
\hline & 6 & 1,22 & 7 & 5,73 & & \\
\hline & 7 & 1,14 & 14 & 12,2 & & \\
\hline & 8 & 1,57 & 22 & 14,01 & & \\
\hline & 9 & 1,22 & 9 & 7,3 & & \\
\hline \multirow{12}{*}{ II } & 10 & 2.09 & 0 & 0 & \multirow[t]{12}{*}{558} & \multirow[t]{12}{*}{21,24} \\
\hline & 11 & 0,18 & 1 & 1,25 & & \\
\hline & 12 & 7,38 & 41 & 5,69 & & \\
\hline & 13 & 5 & 132 & 26,4 & & \\
\hline & 14 & 1,8 & 2 & 1,1 & & \\
\hline & 15 & 1,5 & 165 & 110 & & \\
\hline & 16 & 2,49 & 7 & 2,81 & & \\
\hline & 17 & 2,93 & 7 & 2,3 & & \\
\hline & 18 & 0,8 & 20 & 25 & & \\
\hline & 19 & 1,54 & 51 & 33,11 & & \\
\hline & 20 & 0,85 & 22 & 25,88 & & \\
\hline & 31 & 1,8 & 110 & 61,1 & & \\
\hline \multirow{13}{*}{ III } & 21 & 0,27 & 0 & 0 & \multirow[t]{13}{*}{79} & \multirow[t]{13}{*}{5,2} \\
\hline & 22 & 0,27 & 0 & 0 & & \\
\hline & 23 & 1,1 & 5 & 4,54 & & \\
\hline & 24 & 0,03 & 0 & 0 & & \\
\hline & 25 & 2,15 & 0 & 0 & & \\
\hline & 26 & 0,49 & 0 & 0 & & \\
\hline & 27 & 0,57 & 22 & 38,6 & & \\
\hline & 28 & 0,16 & 7 & 43,75 & & \\
\hline & 29 & 1,87 & 6 & 3,2 & & \\
\hline & 30 & 1,14 & 21 & 18,42 & & \\
\hline & 32 & 2,4 & 6 & 2,5 & & \\
\hline & 33 & 3,1 & 8 & 2,58 & & \\
\hline & 34 & 1,67 & 4 & 2,39 & & \\
\hline \multirow{3}{*}{ IV } & 35 & 1,83 & 8 & 4,37 & \multirow[t]{2}{*}{167} & \multirow[t]{2}{*}{34,9} \\
\hline & 36 & 2,95 & 159 & 53,89 & & \\
\hline & 37 & 2,42 & 149 & 61,6 & \multirow[t]{3}{*}{219} & \multirow[t]{3}{*}{21,2} \\
\hline \multirow[t]{2}{*}{ V } & 38 & 0,50 & 0 & 0 & & \\
\hline & 39 & 7,41 & 70 & 9,44 & & \\
\hline \multirow{5}{*}{ VI } & 40 & 4,21 & 0 & 0 & \multirow[t]{5}{*}{59} & \multirow[t]{5}{*}{5,3} \\
\hline & 41 & 3,01 & 51 & 16,94 & & \\
\hline & 42 & 2,44 & 2 & 0,81 & & \\
\hline & 43 & 1,20 & 0 & 0 & & \\
\hline & 44 & 0,33 & 6 & 6 & & \\
\hline
\end{tabular}

Fonte: dados da pesquisa, 2016.

De maneira geral, nos resultados encontrados neste estudo, constatou-se que o estágio de desenvolvimento com o maior número de indivíduos é o estágio dos reprodutivos jovens, com 669 árvores registradas (Figura 2) e densidade de 8,4 ind/ha, que, segundo Lima (2008), são indivíduos que estão no início da fase reprodutiva, seguida pelo estágio dos reprodutivos maduros, 360 registros, com densidade de 4,5 ind/ha, e juvenis, com 125 e densidade de 1,57 ind/ha. A autora citada encontrou resultado diferente em análise da estrutura populacional de mangabeiras, no Cerrado, em que houve maior número de indivíduos no estágio de juvenis (71,3 ind/ha), seguido por reprodutivos jovens (15 ind/ha) e reprodutivos maduros $(6,7 \mathrm{ind} / \mathrm{ha})$. 


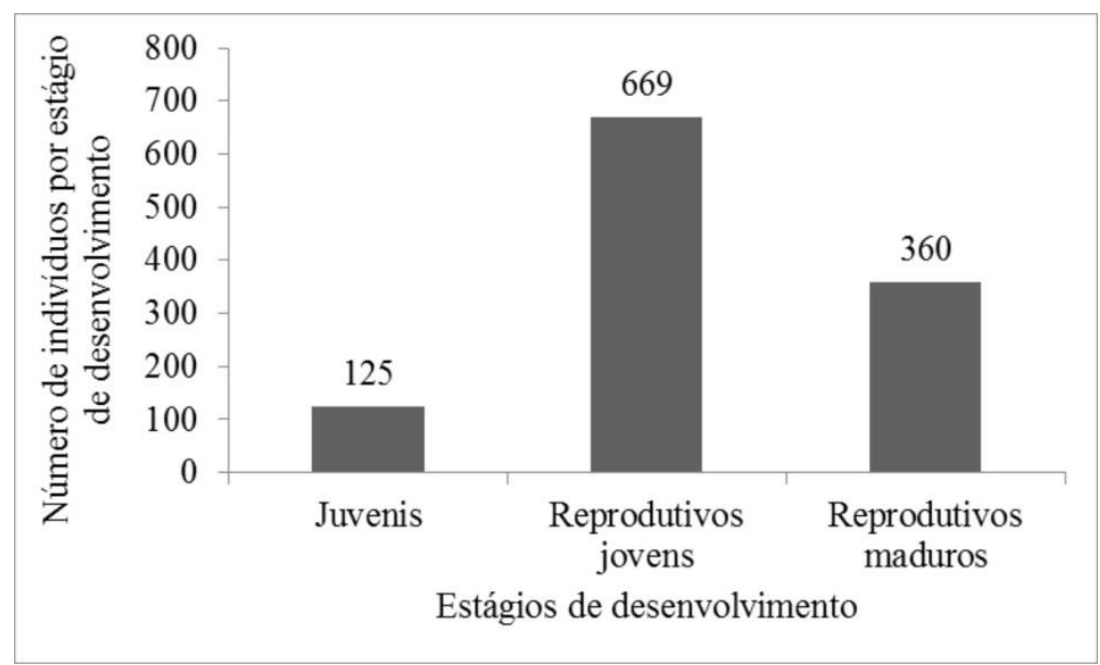

Figura 2: Número de indivíduos por estágio de desenvolvimento no PAE São Sebastião, Pirambu, Sergipe. Fonte: dados da pesquisa, 2016.

Oito lotes $(4,9,13,14,16,17,28$ e 44) apresentaram predominância de indivíduos reprodutivos maduros, 18 lotes $(6,7,11,12,15,18,19,20,23,27,29,30,31,33,34,35,36$ e 37) apresentaram predominância de reprodutivos jovens; apenas um lote (39) apresentou predominância de indivíduos juvenis. Apenas o lote 39, situado na área V, não acompanhou a tendência observada nos outros lotes, apresentando distribuição diamétrica com predominância de indivíduos nas classes menores e redução acentuada no sentido das classes maiores, modelo do "J invertido" (Figura 3). Geralmente, a estrutura populacional com predomínio de indivíduos mais jovens representa uma população em expansão. Por outro lado, quando há predominância de indivíduos velhos, atingindo as classes maiores, pode significar que a população está se extinguindo, sem que haja novos recrutamentos (MARCOS e MATOS, 2003), resultado encontrado nos lotes $4,9,13,14,16,17$ e 44.

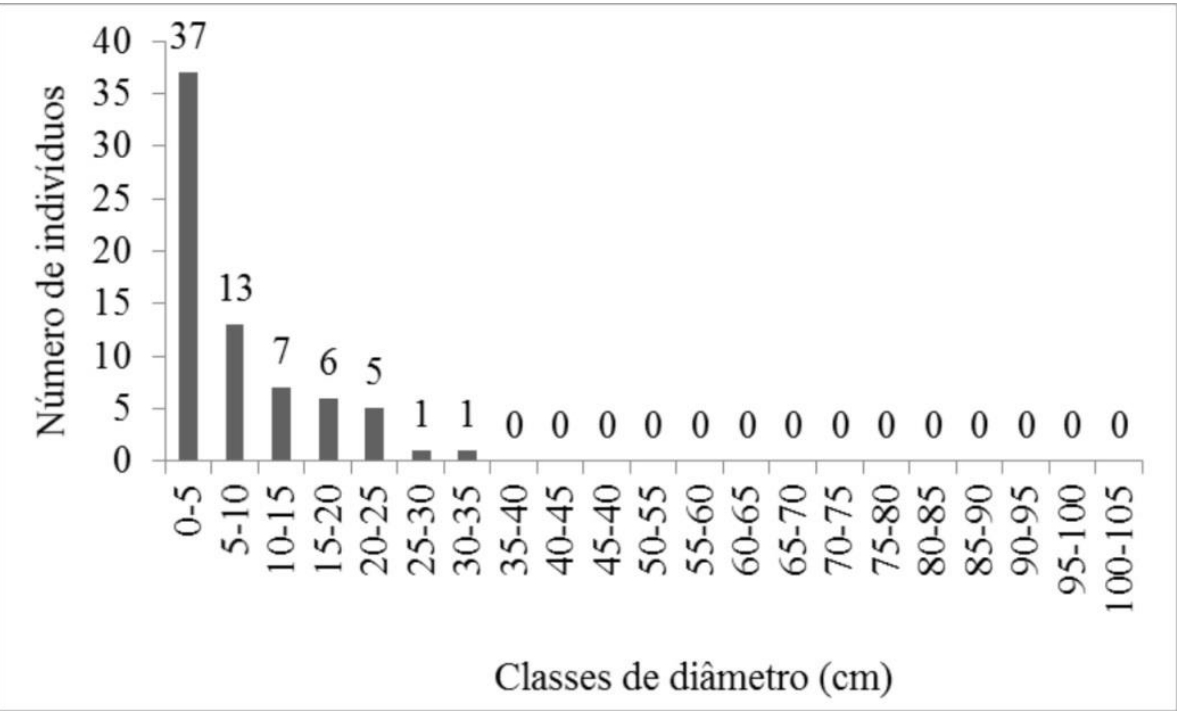

Figura 3: Distribuição de indivíduos de mangabeiras por classe diamétrica, modelo do "J invertido", lote 39, no PAE São Sebastião, Pirambu, Sergipe. Fonte: dados da pesquisa, 2016.

O formato de "J invertido", resultante da distribuição diamétrica, indica que a comunidade é auto regenerativa, ou seja, é uma comunidade vegetal que tem grande potencial para se regenerar (ASSUNÇÃO e FELFILI, 2004). Para Martins (1991), a concentração de indivíduos menores na comunidade não indica ausência de problemas de regeneração, devendo ser considerada com cautela, demonstrando-se a necessidade de uma análise mais detalhada para permitir interpretações mais seguras das distribuições diamétricas.

A maioria dos lotes apresentou uma distribuição descontínua dos diâmetros ao longo das classes, indicando que há um desbalanceamento em determinadas classes diamétricas nessas áreas, portanto é possível que o recrutamento não esteja ocorrendo ao longo das classes de tamanho, mas não significa 
dizer, como afirma Martins (1991), que as populações estejam em declínio. Essas diferenças, segundo Machado et al. (2010), podem estar relacionadas a diversos fatores, abarcando o histórico natural da espécie e o histórico de perturbações dos fragmentos.

Nas áreas I e III (ambientes próximos às áreas encharcadas), a espécie apresentou concentração de indivíduos nas menores classes de diâmetro (de 0-5 a 15-20) e diminuição do número de indivíduos nas classes subsequentes, sendo raro o número de indivíduos com diâmetro acima de $40 \mathrm{~cm}$, na área I, exceto os lotes 4 e 7, com indivíduos alcançando até a classe de $50-55 \mathrm{~cm}$.

Embora os lotes, nessas áreas, possuam populações concentradas nas menores classes de diâmetro, não significa, necessariamente, que estejam em expansão, pois possuem um reduzido número de indivíduos. Estes resultados podem estar relacionados com o uso dessas áreas, já que é comum a queimada para o cultivo de mandioca e a prática de raleamento nos lotes agrícolas, seguida de queimadas para promover o crescimento de gramíneas (Poaceae) para o gado. O raleamento reduz a quantidade de plantas de tamanho intermediário, promovendo o acúmulo de indivíduos nas classes menores (HOFFMAN et al., 2009).

Resultado parecido foi encontrado em população de pequi (Caryocar brasiliense Camb.), no Planalto Central (GIROLDO, 2012), onde a existência de gado, nas áreas de estudo, não influenciou as menores classes de diâmetro, provavelmente porque a pecuária deve ocorrer em baixa intensidade e $\mathrm{o}$ raleamento só comprometeu a densidade de indivíduos nas classes intermediárias.

$\mathrm{Na}$ área II, ambiente com declividade média e acentuada, há, nos lotes, um elevado número de indivíduos nas classes intermediárias, exceto o lote 13, com predominância de indivíduos nas maiores classes, alcançando as classes de diâmetro de 95-100 cm e 100-105 cm. As árvores desse lote estão distribuídas próximas à vegetação nativa, além de estarem próximas entre si, o que promove o sombreamento da área, dificultando o desenvolvimento de novos indivíduos, o que aumenta a competição por luz, uma vez que a mangabeira é uma espécie heliófita e a sua dispersão é barocórica (NOGUEIRA e ALBUQUERQUE, 2006), ou seja, os indivíduos são dispersos próximos à árvorematriz.

Este, entre outros elementos, pode indicar a predominância de indivíduos nas maiores classes de diâmetros, resultando na redução de indivíduos nas menores classes. Outro fator é que, segundo informações dos entrevistados, existem muitas árvores antigas nos lotes, ou seja, estão lá mesmo antes da emancipação do PAE, o que pode explicar o elevado número de indivíduos nas maiores classes de diâmetro em determinados lotes.

Alguns lotes dessa área são pouco explorados pelos entrevistados, já que ainda possuem trechos com vegetação e, assim como ocorre nos lotes da área I e III, as pessoas realizam a queimada para o cultivo de mandioca e plantam gramíneas para pastagem.

Nas áreas IV e V também há predominância de indivíduos nas classes intermediárias em todos os lotes com mangabeiras. Na área VI, os lotes possuem um número reduzido de indivíduos e há predomínio nas classes intermediárias e maiores. Esses lotes possuem grandes trechos com gramíneas e são pouco explorados pelos entrevistados.

Alguns lotes receberam ao longo do tempo maior interferência antrópica, sendo consequente a maior extensão em tamanho. Isto ocorre nos lotes localizados próximos aos remanescentes de vegetação nativa e que avançaram à mata, a fim de aumentar as áreas de cultivo.

Os diferentes níveis de perturbação, manejo e coleta do fruto podem influenciar na perpetuidade dos indivíduos e consequente recrutamento destes nas menores classes (MAGALHÃES et al., 2012), ou seja, os cuidados dos moradores com os pés de mangabeiras, conforme constatado na pesquisa relacionada ao manejo feito pelos entrevistados, podem propiciar a distribuição de indivíduos por classe. Ainda que esses cuidados possam promover melhores condições para a manutenção e desenvolvimento das árvores, garantindo a produção dos frutos nos anos seguintes e consequente disseminação de novos indivíduos, diante dos resultados obtidos nessa pesquisa o manejo realizado por alguns moradores não propiciou, aparentemente, o recrutamento de novos indivíduos nas menores classes de diâmetro.

Pode-se afirmar que a forma de manejo pode gerar resultados diferentes, de acordo com a espécie. Por exemplo, Magalhães et al. (2012), ao analisarem a estrutura diamétrica de baru (Dipteryx alata Vogel) em áreas com diferentes níveis de extração de frutos e antropização, em assentamentos rurais, verificaram que a regeneração era favorecida pelos cuidados empregados pelos assentados.

De acordo com a análise das formas de manejo, realizadas pelos entrevistados, foi possível identificar os lotes com maior intensidade de coleta, respectivamente 15, 36, 37 e 41. Também foi possível observar que o extrativismo ocorre sem critérios em alguns lotes e de maneira desordenada. Nenhum desses lotes atingiu o modelo de "J invertido", mas há predominância de indivíduos nas classes 
intermediárias, por isso não se pode afirmar que o extrativismo esteja causando efeitos negativos nas populações de mangabeiras.

\section{CONCLUSÕES}

Não há padronização nos processos de plantio, coleta e manejo realizados pelos moradores. Cada um tem o seu jeito peculiar de fazê-los, o que indica a ausência e a necessidade de intervenção da assistência técnica junto aos entrevistados.

Os resultados da estrutura populacional demonstraram a predominância de indivíduos reprodutivos maduros em sete lotes, reprodutivos jovens em 18 lotes e juvenis em um lote. Aparentemente, a população de mangabeira, no PAE São Sebastião, não está em crescimento, pois apresenta predominância de indivíduos distribuídos nas classes de diâmetro intermediárias.

As intensas perturbações geradas nos lotes, ocasionadas pelo desmatamento para a expansão das áreas de cultivo, o tipo de manejo e a coleta do fruto, podem estar entre as causas do empobrecimento da regeneração natural e podem estar prejudicando o recrutamento de indivíduos nas classes de diâmetro iniciais.

É necessário desenvolver estudos contínuos para o monitoramento das áreas de coleta, atrelados à dinâmica populacional e à produção dos frutos, para melhor obter conclusões se há riscos de extinção local da espécie - devido ao baixo estoque de indivíduos nas classes de diâmetro iniciais - e se o extrativismo é sustentável.

As informações etnobotânicas poderão contribuir para a gestão e desenvolvimento do PAE e elas são consideradas relevantes para ações estratégicas que visem ao manejo e à conservação das mangabeiras, bem como enfatizar a importância da valorização do conhecimento das populações que convivem diretamente com os recursos naturais.

O presente estudo reafirma a relevância da pesquisa científica de característica interdisciplinar, estendendo a visão do problema e inserindo diversos olhares nas reflexões finais.

\section{AGRADECIMENTOS}

À CAPES pela concessão da bolsa de Mestrado; aos motoristas do setor de transportes da Universidade Federal de Sergipe; aos moradores do PAE São Sebastião por fornecerem estadia, alimentação e compartilhamento de seus conhecimentos.

\section{REFERÊNCIAS}

AGUIAR FILHO, S. P.; BOSCO, J.; ARAÚJO, L. A. A mangabeira (Hancornia speciosa Gomes): domesticação e técnicas de cultivo. João Pessoa: Emepa-PB, 1998.

ALBUQUERQUE, U. P. de. Introdução à etnobotânica. 1. ed. Recife: Bagaço, 2002.

ALBUQUERQUE, U. P.; LUCENA, R. F. P.; ALENCAR, N. L. Métodos e técnicas para coleta de dados etnobiológicos. In: ALBUQUERQUE, U. P.; LUCENA, R. F. P.; CUNHA, L. V. F. C. (Orgs.). Métodos e técnicas na pesquisa etnobiológica e etnoecológica. Pernambuco: NUPEA, 2010. p. 39-64.

ARAÚJO, T. A. S.; ALBUQUERQUE, U. P. (Orgs.). Encontros e desencontros na pesquisa etnobiológica e etnoecológica: os desafios do trabalho em campo. Recife: Nupeea, 2009.

ASSUNÇÃO, S. L.; FELFILI, J. M. Fitossociologia de um fragmento de cerrado sensu stricto na APA do Paranoá, DF, Brasil. Acta Botânica Brasilica, v. 18, p. 903-909, 2004. doi: 10.1590/S0102-33062004000400021

BERKES, F.; KISLAIOLGLU, M.: FOLKE, C.; GADGIL, M. Exploring the basic ecological unit: ecosystemlike concepts in traditional societies. Ecosystems, v. 200, n. 1, p. 409-415, 1998. Disponível em: https://www.jstor.org/stable/3658673?seq=1\#page_scan_tab_contents

BRASIL. Resolução 196 de 10 de outubro de 1996. Conselho Nacional de Saúde. Dispõe sobre diretrizes e normas regulamentadoras de pesquisas envolvendo seres humanos e dá outras providências. Brasília: Ministério de Saúde, 1996.

BRASIL. Lei ${ }^{\circ} \mathbf{1 2 . 6 5 1}$, de 25 de maio de 2012. Dispõe sobre a proteção da vegetação nativa; altera as Leis $\mathrm{n}^{\mathrm{os}}$ 6.938, de 31 de agosto de 1981, 9.393, de 19 de dezembro de 1996, e 11.428, de 22 de dezembro de 2006; revoga as Leis nos 4.771, de 15 de setembro de 1965, e 7.754, de 14 de abril de 1989, e a Medida Provisória no 2.166-67, de 24 de agosto de 2001; dá outras providências. Brasília: DOU de 21/5/2012.

BRITES, A. D.; MORSELLO, C. Efeitos ecológicos da exploração de produtos florestais não madeireiros: uma revisão sistemática. Desenvolvimento e Meio Ambiente, 36, 2016. doi: 10.5380/dma.v36i0.43924

CMMAD - Comissão Mundial sobre Meio Ambiente e Desenvolvimento. Nosso futuro comum. Rio de Janeiro: Fundação Getúlio Vargas, 1987.

FERNANDES, T.; MOTA, D. M. "É sempre bom ter o nosso dinheirinho": sobre a autonomia da mulher no extrativismo da mangaba no Pará. Revista de Economia e Sociologia Rural (Impresso), v. 52, n. 1, p. 9-24, 2014. doi:10.1590/S0103-20032014000100001 
FRAGA, R. G. R. Análise ecodinâmica da Reserva Biológica de Santa Isabel. AGIRAS: Revista AGIR de Ambiente e Sustentabilidade, v. 2, n. 1, p. 28, 2010.

GIROLDO, A. B. Efeitos dos gradientes ecológicos e antrópicos na estrutura e densidade populacional de Caryocar brasiliense Cambess. (pequizeiro) no Cerrado do Planalto Central. 2012. 45 f. Dissertação de Mestrado (Mestrado em Ecologia) - Universidade de Brasília, Brasília, 2012.

GOMES, L. J.; GOMES, M. A. O.; JESUS, N. B. de. Aspectos socioambientais da atividade extrativista de produtos florestais não madeireiros: os casos da fava-d'anta (Dimorphandra sp.) e da aroeira-da-praia (Schinus terebinthifolius Raddi). In: ALBUQUERQUE, U. P. de; HANAZAKI, N. (Orgs.) Árvores de valor e o valor das árvores: pontos de conexão. Recife: Nupeea, 2010.

GUIVANT, J. S. Heterogeneidade de conhecimentos no desenvolvimento sustentável. Cadernos de Ciência \& Tecnologia, v. 14, n. 3, p. 411-446, 1997.

HOFFMAN, W. A.; ADASME, R.; HARIDASAN, M.; CARVALHO, M. T.; GEIGER, E. L.; PEREIRA, M. A. B.; GOTSCH, S. G.; FRANCO, A. C. Tree topkill, not mortality, governs the dynamics of savanna-forest boundaries under frequent fire in Central Brazil. Ecology, v. 90, n. 5, p. 1326-1337, 2009. doi: 10.1890/08-0741.1 HOMMA, A. K. O. Extrativismo vegetal ou plantio: qual a opção para a Amazônia? Estudos Avançados, v. 26, n. 74, p. 167-186, 2012. doi: 10.1590/S0103-40142012000100012.

INCRA. Portaria no 268 de 23 de outubro de 1996. Dispõe sobre a criação da modalidade de Assentamento Agroextrativista. Brasília: DOU: nº 208, de 25/12/1996.

INCRA. Plano de desenvolvimento do projeto de assentamento agroextrativista São Sebastião. Pirambu: INCRA, 2009.

KRAMER, P. J.; KOZLOWSKI, T. T. Fisiologia das árvores. Lisboa: Fundação Calouste Gulbenkian, 1972. LEDERMAN, I. E.; SILVA JUNIOR, J. F.; BEZERRA, J. E. F.; ESPÍNDOLA, A. C. M. Mangaba (Hancornia speciosa Gomes). São Paulo: Jaboticaba, Série 2, 2000.

LEFREVE, F.; LEFREVE, A. M. C. Depoimento e discursos: uma proposta de análise em pesquisa social. Brasília: Liber Livro, 2005.

LIMA, L. P. Etnobotânica quantitativa de plantas do Cerrado e extrativismo de mangaba (Hanconia speciosa Gomes) no Norte de Minas Gerais: implicações para o manejo sustentável. 2000. Dissertação (Mestrado em Ecologia) - UNB, Brasília, 2008.

LIMA, I. L. P.; SCARIOT, A. Boas práticas de manejo para o extrativismo sustentável da Mangaba. Brasília: Embrapa Recursos Genéticos e Biotecnologia, 2011. MACHADO, E. L. M.; GONZAGA, A. P. D.; CARVALHO, W. A. C.; SOUZA, J. S.; HIGUCHI, P.; SANTOS, R. M.; SILVA, A. C.; OLIVEIRA-FILHO, A. T. Flutuações temporais nos padrões de distribuição diamétrica da comunidade arbóreo-arbustivo e de 15 populações em um fragmento florestal. Revista Árvore, v. 34, n. 4, p. 723-732, 2010. doi: 10.1590/S0100-67622010000400017

MAGALHÃES, L. C. S.; FARIA, R. R.; DAMASCENO, J. Geraldo, A. Estrutura diamétrica de Dipteryx alata vog. em áreas com diferentes níveis de extração de frutos e antropização. Revista Brasileira de Agroecologia, v. 7, n. 3, p. 135-142, 2012.

MARCOS, C. S.; MATOS, D. M. S. Estrutura de populações de palmiteiro (Euterpe edulis Mart.) em áreas com diferentes graus de impactação na floresta da tijuca, RJ. Floresta e Ambiente, v. 10, n. 1, p. $27-37,2003$.

MARCONI, M. A.; LAKATOS, E. M. Fundamentos de metodologia científica. 7. ed. São Paulo: Atlas, 2010.

MARTINS, F. R. Estrutura de uma floresta mesófila. São Paulo: Unicamp, 1991.

MING, L. C.; FERREIRA, M. I.; GONÇALVES, G. G. Pesquisas agronômicas das plantas medicinais da Mata Atlântica regulamentadas pela ANVISA. Revista Brasileira de Plantas Medicinais, v. 14, p. 131-137, 2012. doi: 10.1590/S1516-05722012000500001

NOGUEIRA, R. J. M. C; ALBUQUERQUE, M. B. Ecofisiologia. In: SILVA-JUNIOR, J. F. da; LÊDO, A. da S. (Orgs.) A cultura da mangaba. Aracaju: EMBRAPA Tabuleiros Costeiros, 2006. p. 35-42.

OLIVEIRA, D. M. de; SANTOS, L. A. S.; GOMES, L. J. Uso da flora em assentamento agroextrativista do litoral de Sergipe, Brasil. Guaju, v. 4, p. 163-183, 2018.

PARENTE, T. V.; BORGO, L. A.; MACHADO, J. W. B. Características físico-químicas de frutos de mangaba (Hancornia speciosa Gomes) do cerrado da região geoeconômica do Distrito Federal. Ciência e Cultura, v. 37 , n. 1, p. 95-98, 1985.

PCIHN. Projeto cadastro da infraestrutura hídrica do nordeste. Diagnóstico do município de Pirambu. Pirambu, 2008.

PETERS, C. M. Sustainable harvest of non-timber plant resources in tropical moist forest: an ecological primer. Washington, D.C.: Biodiversity Support Program, 1994.

POSEY, D.A. Etnobiologia: teoria e prática. In: RIBEIRO, B. (Ed.). Suma etnobiológica brasileira. Petrópolis: Vozes/Finep, 1987. p. 15-251.

RODRIGUES, R. F. de. A. et al. Mapa do extrativismo da mangaba em Sergipe: situação atual e perspectivas. Brasília, DF: Embrapa, 2017. 
SANTANA, J. U. R.; CARVALHO, I. C. A.; GOMES, L. J. Em busca da sustentabilidade: mensuração e avaliação da dimensão social em assentamento agroextrativista no estado de Sergipe. Scientia plena, v. 8, n. 8, p. 1-11. 2012.

SCHMITZ, H.; MOTA, D. M. da; SILVA-JUNIOR, J. J. da; FRANCISCO, da J. Gestão coletiva de bens comuns no extrativismo da mangaba no nordeste do Brasil. Ambiente \& Sociedade, 12 (2), 273-292, 2009. doi: 10.1590/S1414-753X2009000200005

SEMARH-SRH. Atlas digital sobre recursos hídricos de Sergipe. CD-ROM. 2015.

SILVA JUNIOR, J. J. da; MOTA, D. M. da; JUNQUEIRA, N. T. V. Representações de uma população tradicional de catadores acerca do extrativismo da mangaba no Litoral Sul de Sergipe. In: Simpósio Brasileiro sobre a Cultura da Mangaba. Anais... Aracaju, 2003.

TICKTIN, T. The ecological implications of harvesting non-timber forest products. Journal of Applied Ecology, v. 41, p. 11-21, 2004. doi: 10.1111/j.1365-2664.2004.00859.x

VERDEJO, M. E. Diagnóstico rural participativo: guia prático DRP. Brasília, DF: Ministério do Desenvolvimento Agrário (MDA)/Secretaria da Agricultura Familiar, 2007.

VIEIRA NETO, R. D.; CINTRA, F. L. D.; LEDO, A. S.; SILVA JUNIOR, J. F.; COSTA, J. L. S.; SILVA, A. A. $G$ da; CUENCA, M. A. G. Sistema de produção de mangaba para os tabuleiros costeiros e baixadas litorâneas. Aracaju: EMBRAPA-CPTAC, 2006. 